\title{
Clinical Outcome of Class II direct composite restorations using total-Cetch versus selective etch adhesives
}

\author{
DILAWAR SULTAN ${ }^{1}$, ZUHAIR ARIF ${ }^{2}$, ESSA ARSHAD ${ }^{3}$, SABA MUSHTAQ ${ }^{4}$, KINZA KHALID ${ }^{5}$, MAHEEN AHMAD ${ }^{6}$ \\ ${ }_{1,2}$ Assistant Professor, Department of Operative Dentistry, Akhtar Saeed medical and dental college, Lahore, Pakistan. \\ 3,4,5,6 House Officer, Akhtar Saeed Medical and Dental College, Lahore, Pakistan. \\ Correspondence to Dr Zuhair Arif, drzuhairarif@gmail.com
}

\begin{abstract}
Background: The composite restoration of anterior is always a challenging job.

Aim: To compare the clinical outcome of class 2 direct composite restorations using total-etch and selective etch adhesives, according to USPHS criteria.

Methods: One hundred patients were included in this randomized controlled clinical trial study at Operative Dentistry department of LMDC, Lahore. They were divided in two groups. Group 1 for total etch technique, group 2 for selective etch technique enamel was etched with $37 \%$ phosphoric acid for 20 second and then washed thoroughly with water for 5-10 seconds and was dried with air for 5 seconds till frosty white and bond with self etch. Results: The majority of patients were in the age range of $25-31$ years, $25(50 \%)$ patients used total etch technique and $22(44 \%)$ patients used selected etch technique. When compare the overall rating for restorations, 38 patients (76\%) have acceptable restoration in total etch technique and 46 patients $(92 \%)$ in selected etch technique. Statistically the difference was significant $(\mathrm{P}<0.05)$.

Conclusion: Selected etch technique presented a successful clinical performance over total etch technique for Class II restorations.

Keywords: Class II direct composition restoration, Total etch technique, Selected etch technique.
\end{abstract}

\section{INTRODUCTION}

Composite bond to prepared tooth structure with the help of dentin adhesives, two strategies are used. The total etch technique which utilizes $37 \%$ orthophosphoric acid to completely eliminate the smear layer and smear plugs which are created as a result of tooth preparation, and the self etch technique which involves the modification of smear layer by using mild acidic monomer without using a water rinse ${ }^{1-5}$.

Self etch adhesives have advantage of being simple, less technique sensitive and causing less postoperative sensitivity because they retain the smear plugs and there is no discrepancy in the depth of dentin demineralization and adhesive penetration ${ }^{6-8}$. In this rinsing step is eliminated so the problem of controlling levels of moisture in the prepared dentin also does not exist. However, enamel leakage has been reported in class II and V restorations when self etch adhesives are used in enamel/dentin, because self etch monomer are not strong enough for complete enamel demineralization ${ }^{9,10}$.

According to a study on "2 years clinical evaluation of 2 step etch and rinse and a 2 step self etch adhesive system in class II restorations", results of marginal discoloration, postoperative sensitivity and secondary caries were $100 \%$ acceptable at baseline, 6 months and 1 year $^{9}$.

The rationale of this study is to evaluate the clinical outcome of class 2 restorations using total-etch and selective etch adhesives at baseline (immediately after restoration) and 6 months post operative. Although a number of literature is published on these methods with insignificant difference ${ }^{11-15}$. The insignificant difference is may be due to different methodology. But on the other

Received on 05-02-2021

Accepted on 21-05-2021 hand is also reported that total etch adhesives don't bond well to dentin and self etch adhesives don't bond well with enamel.

The objective of this study was to compare the clinical outcome of class 2 direct composite restorations using total-etch and selective etch adhesives, according to USPHS criteria.

\section{METHODOLOGY}

The sample size was estimated at 100 cases using $95 \%$ confidence level, $80 \%$ power of test taking an expected percentage of postoperative sensitivity as $94 \%$ in total etch ${ }^{6}$ and $100 \%$ in self etch?

Sampling technique was non-probability purposive sampling. Following samples were included: Medium size class 2 cavity (4-8 mm mesiodistal and buccolingual width), proximal box depth maximum $(4 \mathrm{~mm})$, patients having two similar cavities in contralateral quadrants, good oral hygiene and both genders.

After taking informed consent and ethics approval one hundred and ten teeth were selected for direct composite resin restorations fulfilling our inclusion criteria from Operative Dentistry department of Lahore Medical and Dental College, Lahore. Shade selection was done by placing VITAPAN shade guide next to the effected tooth and observed from $21 \mathrm{~cm}$ distance with patient facing window in day light. Posterior tooth shade was kept one step darker then the anterior tooth. Patient was asked whether he/she likes the selected shade. Shade selection was finalized in the Performa with patient's consent. After selecting shade tooth was isolated with rubber dam. Modified preparation for composite which have neither specified walls configurations nor specific pulpal and axial depth and preferably have margins in enamel was prepared using round diamond bur. Extensions of margins and depth of modified tooth preparation are directed solely 
to the extent of the carious lesion, thus avoiding unnecessary tooth reduction. Split mouth technique was used for selecting restorations material.

Group 1: For total etch technique, enamel and dentin was conditioned with $37 \%$ phosphoric acid for 20 second and then washed thoroughly with water for 5-10 seconds and enamel was dried with air for 5 seconds till frosty white and dentin was dried gently and left slightly moist, then 2 to 3 coats of unfilled adhesive resin was applied to have 100 micron meters thickness and was thinned with air for 5 second when ripples stop forming and cured with blue LED light for 20 seconds.

Group 2: For selective etch technique enamel was etched with $37 \%$ phosphoric acid for 20 second and then washed thoroughly with water for 5-10 seconds and was dried with air for 5 seconds till frosty white and bond with self etch. In self etch technique, 2-3 coats of self etch bond was applied and thinned with air for 5 seconds when ripples stop forming. Then it was cured with Blue LED light for 20 seconds.

Clinical acceptability of restorations were checked according to the modified USPHS $^{6}$ criteria with naked eye and sickle shaped explorer 6 months later.

Data analysis: Qualitative variables like post operative sensitivity, marginal discoloration and secondary caries and presented in form of percentage and frequency. Ratings for restorations at baseline and follow-up examinations were compared using the chi-square test for each category to see the outcome of each restoration. Age was presented in the form of mean \pm standard deviation (SD).

\section{RESULTS}

The majority of patients (Table 1,2,3) were in the age range of 25-31 years, $25(50 \%)$ patients used total etch technique and $22(44 \%)$ patients used selected etch technique. When compare the overall rating for restorations, 38 patients $(76 \%)$ have acceptable restoration in total etch technique and 46 patients (92\%) in selected etch technique. Statistically the difference was significant $(P<0.05)$ (Table 4).

Table 1: Distribution of patients by marginal discoloration $(n=100)$

\begin{tabular}{|l|c|c|c|c|}
\hline \multirow{2}{*}{ Marginal discoloration } & \multicolumn{2}{|c|}{ Group 1 } & \multicolumn{2}{c|}{ Group 2 } \\
\cline { 2 - 5 } & No. & $\%$ & No. & $\%$ \\
\hline Alpha (Good) & 30 & 60.0 & 35 & 70.0 \\
\hline Bravo (Satisfactory) & 12 & 24.0 & 13 & 26.0 \\
\hline Charlie (Unsatisfactory) & 8 & 16.0 & 2 & 4.0 \\
\hline
\end{tabular}

Table 2: Distribution of patients by postoperative sensitivity $(\mathrm{n}=100)$

\begin{tabular}{|l|c|c|c|c|}
\hline \multirow{2}{*}{$\begin{array}{l}\text { Postoperative } \\
\text { sensitivity }\end{array}$} & \multicolumn{2}{|c|}{ Group 1 } & \multicolumn{2}{c|}{ Group 2 } \\
\cline { 2 - 5 } & No. & $\%$ & No. & $\%$ \\
\hline Alpha (Good) & 34 & 68.0 & 40 & 80.0 \\
\hline Bravo (Satisfactory) & 8 & 16.0 & 6 & 12.0 \\
\hline Charlie (Unsatisfactory) & 8 & 16.0 & 4 & 8.0 \\
\hline
\end{tabular}

Table 3: Distribution of patients by secondary caries $(n=100)$

\begin{tabular}{|l|c|c|c|c|}
\hline \multirow{2}{*}{ Secondary caries } & \multicolumn{2}{|c|}{ Group 1 } & \multicolumn{2}{c|}{ Group 2 } \\
\cline { 2 - 5 } & No. & $\%$ & No. & $\%$ \\
\hline Alpha (Good) & 36 & 72.0 & 43 & 86.0 \\
\hline Bravo (Satisfactory) & 6 & 12.0 & 5 & 10.0 \\
\hline Charlie (Unsatisfactory) & 8 & 16.0 & 2 & 4.0 \\
\hline
\end{tabular}

Table 4: Overall scoring in both groups $(n=100)$

\begin{tabular}{|l|c|c|c|c|}
\hline \multirow{2}{*}{ Overall score } & \multicolumn{2}{|c|}{ Group 1 } & \multicolumn{2}{c|}{ Group 2 } \\
\cline { 2 - 5 } & No. & $\%$ & No. & $\%$ \\
\hline Acceptable & 38 & 76.0 & 46 & 92.0 \\
\hline Unacceptable & 12 & 24.0 & 4 & 8.0 \\
\hline$X^{2}=4.76, \mathrm{df}=1, \mathrm{P}=0.029$ & \multicolumn{4}{l}{} \\
\hline
\end{tabular}

\section{DISCUSSION}

Despite many researches there has been great interest recently in the application and use of composite restorations. Present study was designed to compare the results of total etch technique with selected etch technique using USPHS criteria. The USPHS criteria was used as it is found to be a reliable method for assessment of various parameters of restorations such as margins integrity, discoloration of margins, caries, post-op sensitivity and shade selection ${ }^{16-18}$.

The results of the present study showed that there was no difference in success of marginal adaptation and secondary caries while comparing the results of total etch technique with selected etch technique using USPHS criteria. This may be due to the fact that margins of preparation were left within enamel and only those cases were selected that possessed no caries or restoration before start of restoration ${ }^{19,20}$.

The results showed that selected etch method produced higher bond strength which is good for good margins of restorations and proper seal of it therefore it is recommended that enamel cavo-surface margins should be etched too before application of self etching method ${ }^{18}$. It is recommended that dentine cavo-surface margins should not be etched before application of self etching method ${ }^{19}$.

The acid-etching technique prior to self-etching method in Group II may cause no significant difference between the 2 methods. The results showed that strength was same at all the cavo-surface margins between the 2 methods except at cervical region. Therefore, the clinical result of 2 systems showed good performance of 2 systems in terms of periodontal reaction, margins, discoloration, caries and postoperative sensitivity.

The clinical result of 2 systems showed good performance of 2 systems in terms of cavosur-face marginal discoloration, margins, secondary carious lesions and gingival response. This may be due to selection of non-smokers, good oral hygiene, good amount of curing, good performance of adhesives, less masticatory forces, adhesion to larger area of tooth, and removal of stains ${ }^{21-25}$.

There are several limitations of this study such as small sample size and single centric study however within these limitations the results showed that selected etch technique presented a successful clinical performance over total etch technique for Class II restorations.

\section{CONCLUSION}

Selected etch technique presented a successful clinical performance over total etch technique for Class II restorations.

Conflict of interest: None 


\section{REFERENCES}

1. Ghiorghe CA, Gamen AC, Tirca T, Andrian S, Melian A, Pancu G. Salceanu M. Laser Therapy Evaluation in Complications of Restorations by Total-Etch Technique. Rev. Chim. 2018 Apr 1;69(4).

2. Gupta A, Tavane P, Gupta PK, Tejolatha B, Lakhani AA, Tiwari R, Kashyap S, Garg G. Evaluation of microleakage with total etch, self etch and universal adhesive systems in class $V$ restorations: an in vitro study. Journal of clinical and diagnostic research: JCDR. 2017 Apr;11(4):ZC53.

3. Meerbeek BV, Yoshihara K, Van Landuyt K, Yoshida Y, Peumans M. From Buonocore's Pioneering Acid-Etch Technique to Self-Adhering Restoratives. A Status Perspective of Rapidly Advancing Dental Adhesive Technology. Journal of Adhesive Dentistry. 2020 Jan 1;22(1).

4. Meraji N, Camilleri J. Bonding over dentin replacement materials. Journal of endodontics. 2017 Aug 1;43(8):1343-9.

5. Jayasheel $A$, Niranjan $N$, Pamidi $H$, Suryakanth $M B$. Comparative Evaluation of shear Bond Strength of universal Dental Adhesives-An in vitro study. Journal of clinical and experimental dentistry. $2017 \mathrm{Jul} ; 9(7)$ :e892.

6. Horikiri F, Narita Y, Yoshida T. Excellent wet etching technique using pulsed anodic oxidation for homoepitaxially grown GaN layer. Japanese Journal of Applied Physics. 2018 Jul 9;57(8):086502.

7. Stape TH, Tjäderhane L, Abuna G, Sinhoreti MA, Martins LR, Tezvergil-Mutluay A. Optimization of the etch-and-rinse technique: New perspectives to improve resin-dentin bonding and hybrid layer integrity by reducing residual water using dimethyl sulfoxide pretreatments. Dental Materials. $2018 \mathrm{Jul}$ 1;34(7):967-77.

8. Marashdeh $M Q$, Gitalis $R$, Levesque $C$, Finer $Y$. Enterococcus faecalis hydrolyzes dental resin composites and adhesives. Journal of endodontics. 2018 Apr 1;44(4):60913.

9. Tsujimoto A, Barkmeier WW, Takamizawa $\mathrm{T}$, Watanabe $\mathrm{H}$, Johnson WW, Latta MA, Miyazaki M. Comparison between universal adhesives and two- step self- etch adhesives in terms of dentin bond fatigue durability in self- etch mode. European journal of oral sciences. 2017 Jun;125(3):215-22.

10. Takamizawa T, Barkmeier WW, Sai K, Tsujimoto A, Imai A, Erickson RL, Latta MA, Miyazaki M. Influence of different smear layers on bond durability of self-etch adhesives. Dental Materials. 2018 Feb 1;34(2):246-59.

11. Suda S, Tsujimoto A, Barkmeier WW, Nojiri $K$, Nagura $Y$, Takamizawa T, Latta MA, Miyazaki M. Comparison of enamel bond fatigue durability between universal adhesives and twostep self-etch adhesives: effect of phosphoric acid preetching. Dental materials journal. 2018 Mar 26;37(2):244-55.

12. Turkistani A, Almutairi M, Banakhar N, Rubehan R, Mugharbil S, Jamleh A, Nasir A, Bakhsh T. Optical evaluation of enamel microleakage with one-step self-etch adhesives. Photomedicine and laser surgery. 2018 Nov 1;36(11):589-94.
13. Yonekura K, Hosaka K, Tichy A, Taguchi K, Ikeda M, Thanatvarakorn O, Prasansuttiporn T, Nakajima M, Tagami J. Air-blowing strategies for improving the microtensile bond strength of one-step self-etch adhesives to root canal dentin. Dental Materials Journal. 2020 Sep 28;39(5):892-9.

14. Meerbeek BV, Yoshihara K, Van Landuyt K, Yoshida Y, Peumans M. From Buonocore's Pioneering Acid-Etch Technique to Self-Adhering Restoratives. A Status Perspective of Rapidly Advancing Dental Adhesive Technology. Journal of Adhesive Dentistry. 2020 Jan 1;22(1).

15. Turkistani A, Almutairi M, Banakhar N, Rubehan R, Mugharbil S, Jamleh A, Nasir A, Bakhsh T. Optical evaluation of enamel microleakage with one-step self-etch adhesives. Photomedicine and laser surgery. 2018 Nov 1;36(11):589-94.

16. Hass V, Cardenas AF, Siqueira FS, Pacheco RR, Zago PM, Silva DO, Bandeca MC, Loguercio AD. Bonding performance of universal adhesive systems applied in etch-and-rinse and self-etch strategies on natural dentin caries. Operative dentistry. 2019 Sep;44(5):510-20.

17. Zecin-Deren A, Sokolowski J, Szczesio-Wlodarczyk A, Piwonski I, Lukomska-Szymanska M, Lapinska B. Multi-layer application of self-etch and universal adhesives and the effect on dentin bond strength. Molecules. 2019 Jan;24(2):345.

18. Pupo YM, Bernardo CF, de Souza FF, Michél MD, Ribeiro CN, Germano S, Maluf DF. Cytotoxicity of etch-and-rinse, self-etch, and universal dental adhesive systems in fibroblast cell line 3T3. Scanning. 2017 Jan 10;2017.

19. Selvi VT, Brundha MP. Preference of Self Etch Vs Total Etch among Dental Practitioners in India-A Survey. Indian Journal of Forensic Medicine \& Toxicology. 2020 Oct 1;14(4).

20. Tsujimoto A, Barkmeier WW, Takamizawa $\mathrm{T}$, Watanabe $\mathrm{H}$, Johnson WW, Latta MA, Miyazaki M. Comparison between universal adhesives and two- step self- etch adhesives in terms of dentin bond fatigue durability in self- etch mode. European journal of oral sciences. 2017 Jun;125(3):215-22.

21. Gupta A, Tavane P, Gupta PK, Tejolatha B, Lakhani AA, Tiwari R, Kashyap S, Garg G. Evaluation of microleakage with total etch, self etch and universal adhesive systems in class $\mathrm{V}$ restorations: an in vitro study. Journal of clinical and diagnostic research: JCDR. 2017 Apr;11(4):ZC53.

22. Perdigao J, Geraldeli S, Hodges JS. Total-etch versus selfetch adhesive: effect on postoperative sensitivity. The Journal of the American Dental Association. 2003 Dec 1;134(12):1621-9.

23. Say EC, Nakajima M, Senawongse $P$, Soyman M, Özer F, Ogata M, Tagami J. Microtensile bond strength of a filled vs unfilled adhesive to dentin using self-etch and total-etch technique. Journal of dentistry. 2006 Apr 1;34(4):283-91.

24. Tay FR, Pashley DH, Mak YF, Carvalho RM, Lai SC, Suh BI. Integrating oxalate desensitizers with total-etch two-step adhesive. Journal of dental research. 2003 Sep;82(9):703-7.

25. Duarte Jr S, de Freitas CR, Saad JR, Sadan A. The effect of immediate dentin sealing on the marginal adaptation and bond strengths of total-etch and self-etch adhesives. The Journal of prosthetic dentistry. 2009 Jul 1;102(1):1-9. 